DOI 10.37882/2500-3682.2020.08.06

\title{
СВЯЗЬ САМООЦЕНКИ АКАДЕМИЧЕСКИХ ДОСТИЖЕНИЙ И ПРОГНОСТИЧЕСКОЙ КОМПЕТЕНТНОСТИ БУДУЩИХ ПРОФЕССИОНАЛОВ В ЭКЗАМЕНАЦИОННОЙ СИТУАЦИИ
}

\section{THE RELATIONSHIP OF \\ SELF-ASSESSMENT OF ACADEMIC \\ ACHIEVEMENTS AND PREDICTIVE \\ COMPETENCE OF FUTURE \\ PROFESSIONALS IN THE EXAM SITUATION \\ O. Zhuchenko}

Summary: Adequate self-assessment of academic achievement is one of the resources of stress resistance. The level of mental tension, prognostic competence differs depending on the self-assessment of academic achievements. An inverse correlation of the level of stress with the level of personality-situational prognostic competence in groups of students with inadequate self-assessment of academic achievements was revealed. The results contribute to the development of a program for the development of an adequate self-assessment of academic achievements of students.

Keywords: self-assessment of academic achievement, predictive competence, anticipatory solvency, exam, stress resistance, future professional.

\author{
Жученко Ольга Александровна \\ Старший преподаватель, ФГБОУ ВО «Ижевская \\ государственная сельскохозяйственная академия», \\ 2. Ижевск \\ adlog@mail.ru
}

Аннотация: Адекватная самооценка академических достижений является одним из ресурсов стрессоустойчивости. Уровень психической напряженности, прогностической компетентности отличается в зависимости от самооценки академических достижений. Выявлена обратная корреляция уровня стресса с уровнем личностно-ситуативной прогностической компетентности в группах студентов с неадекватной самооценкой академических достижений. Результаты способствуют разработке программы развития адекватной самооценки академических достижений студентов.

Ключевые слова: самооценка академических достижений, прогностическая компетентность, антиципационная состоятельность, экзамен, стрессоустойчивость, будущий профессионал.

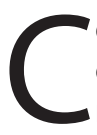
овременный мир пронизан цифровой реальностью, что особенно ярко проявилось в условиях пандемии COVID-19: цифровые системы очень прочно вошли в нашу жизнь не только в сфере интимно-личностного общения, но и в профессиональной, и в образовательной среде, что порождает необходимость формирования и развития новых компетенций у будущих профессионалов. Согласимся с мнением профессора Т.В. Черниговской, утверждающей, что необходимо «сформировать способность жить в цифровом мире и не потерять человечность» [3]. В то же время она подчеркивает, что стрессоустойчивость является одним из важных качеств успешного человека в будущем.

В соответствии с новым ФГОС высшего образования будущий профессионал, в частности, должен уметь выстраивать и реализовывать траекторию саморазвития в течение всей жизни [12]. Саморазвитие невозможно без цели, являющейся осознанным образом предвосхищаемого, желаемого результата, на достижение которого направлено действие человека [13]. Таким образом, в основе целеполагания лежит прогностическая компетентность.
Среди психологических процессов, направленных на предсказание будущего, можно выделить вероятностное прогнозирование, нацеленное на построение математической модели будущего, экспектацию (эмоционально окрашенное и мотивационно подкрепленное ожидание с привлечением характеристик желанное / нежеланное), антиципацию, включающую в себя также и деятельностный аспект [7].

При изучении свойства личности, её устойчивой характеристики, фиксирующей уровень развития антиципационных способностей и представляющей собой определённое состояние системы внутренних ресурсов личности, обеспечивающих успешность прогностической деятельности, часть учёных $[11 ; 14 ; 15 ; 16]$, отождествляют дефиниции «антиципационная состоятельность» и «прогностическая компетентность». Под антиципационной состоятельностью (прогностической компетентностью) понимается способность личности с высокой вероятностью предвосхищать ход событий, прогнозировать развитие ситуаций и собственные реакции на них, действовать с временно-пространственным упреждением [9]. 
Е.В. Макарова [8] определила структуру прогностической компетентности в профессиональной сфере, выделив мотивационно-регулятивный (личностные особенности, регулирующие прогностическую деятельность и лежащие в основе профессиональных решений), операционально-когнитивный (профессиональные знания, отражающие существующие связи и тенденции развития объектов прогноза в рамках профессиональной деятельности) и операционально-поведенческий (поведенческая гибкость, широкий спектр поведенческих реакций) компоненты. Задачам настоящего исследования больше релевантна структура прогностической компетентности, выделенная В.Д. Менделевичем [9]:

- личностно-ситуативная компетентность - способность предвидеть поступки других людей, наступление и различные варианты развития событий,

- пространственная компетентность - моторная преднастройка, ориентация в пространстве,

- временная, или хроноритмологическая, компетентность - способность к распределению и адекватному планированию своего времени.

Работы Н.Н. Ничипоренко [10] показали, что сформированная общая прогностическая компетентность способствует стабильности, уверенности, позитивной жизненной позиции и успешности взаимодействия человека с социальным окружением. Будучи взаимосвязанной с механизмами психологической защиты и копинг - стратегиями, прогностическая компетентность сопряжена с эмоциональной стабильностью, низкой тревожностью, импульсивностью, являющимися признаками психического здоровья, обеспечивая тем самым социальную адаптацию [1; 10; 15]. Предотвращение, снижение частоты, неожиданности и остроты действия стрессогенных факторов позволяет рассматривать прогностическую компетентность как неспецифический копинг - ресурс личности [10].

Учеными проведено множество исследований, подтверждающих, что экзамен является стрессогенной ситуацией $[17 ; 19 ; 20]$. Перед ее началом, как и перед любой другой деятельностью, у студента есть мысленная модель (в форме представления) ожидаемых результатов [7]. В рамках нашего исследования мы систематизировали их в качестве компонентов самооценки академических достижений: желаемая оценка (та, которую студент хочет получить на экзамене), ожидаемая оценка (та, которую он ожидает получить на экзамене), оценка себе, исходя из своего уровня компетентности (перед экзаменом). Под самооценкой академических достижений мы понимаем оценку студентом своих возможностей достичь успеха в образовательном процессе, в частности, при промежуточной и итоговой аттестации. Адекватная самооценка академических достижений (САД), в основе которой лежит прогностическая компетентность, позволяет снизить неопределённость стрессогенной ситуации, подготовиться к ней, что даёт возможность говорить о ней как об одном из ресурсов стрессоустойчивости [6]. Таким образом, развитие адекватности САД составляет актуальность исследования. Выявление связи прогностической компетентности и САД позволит точнее определить механизмы и компоненты развивающей программы, что составляет практическую значимость настоящей работы.

Цель работы: изучение влияния прогностической компетентности на адекватность самооценки академических достижений в экзаменационной ситуации.

Цель достигается через решение следующих задач:

1. анализ научной литературы, выявляющей особенности прогностической компетентности в стрессогенных ситуациях,

2. выявление различия уровня психической напряжённости и значений компонентов прогностической компетентности в зависимости от самооценки академических достижений,

3. изучение корреляции уровня психической напряжённости и компонентов прогностической компетентности в зависимости от адекватности самооценки академических достижений.

Гипотеза состоит из нескольких частей:

1. уровень психической напряженности отличается в зависимости от самооценки академических достижений;

2. значения прогностической компетентности отличаются в группах испытуемых с разным уровнем самооценки академических достижений;

3. уровень психической напряжённости в экзаменационной ситуации влияет на прогностическую компетентность.

Предмет исследования - связь прогностической компетентности и самооценки академических достижений будущих профессионалов в стрессогенной ситуации (на примере экзамена в вузе).

Объект исследования - самооценка академических достижений студентов в экзаменационной ситуации.

Выборку составили 244 студента первых, вторых курсов ФГБОУ ВО «Ижевская государственная сельскохозяйственная академия» агропромышленных направлений подготовки бакалавриата, ветеринарных и экономических специальностей.

Методы: модифицированная методика Дембо-Рубинштейн, определяющая самооценку академических достижений и уровень психической напряженности в экзаменационной ситуации, тест антиципационной состоятельности (прогностической компетентности) ТАС В.Д. Менделевича, беседа, описательная статистика, 
G-критерий знаков, U-критерий Манна-Уитни, коэффициент ранговой корреляции Спирмена. Математическая обработка проводилась с помощью программы SPSS 17.0.

Тест антиципационной состоятельности (прогностической компетентности) В.Д. Менделевича проводился со студентами в обычный учебный день. Данный тест даёт возможность выявить количественные показатели антиципационных (прогностических) способностей по трем составляющим: личностно-ситуативной, пространственной и временной. Модифицированную методику Дембо-Рубинштейн студенты заполняли непосредственно перед началом экзамена, определяя желаемую, ожидаемую оценку, оценку себе, исходя из своего уровня знаний, уровень психической напряжённости в данный момент. Для каждого направления подготовки и специальности был выбран самый стрессогенный экзамен, исходя из беседы со студентами.

Нами выявлено, что адекватно прогнозируют свои результат на экзамене только $16,2 \%$ студентов. Это означает, что желаемая, ожидаемая и оценка себе, исходя из уровня знаний, студентов совпала с реальной оценкой, полученной на экзамене. В данном исследовании выделена группа испытуемых с завышенной желаемой оценкой и адекватными остальными компонентами самооценки академических достижений, так как их оказалось много: $22.1 \%$. Все они хотели получить выше оценку по сравнению с итогом экзамена. Это может говорить об их высоком уровне притязаний и мотивации. Количество учащихся с неадекватной (завышенной и заниженной) самооценкой академических достижений, составившее больше половины выборки (36.8\% и 16.7\% соответственно), подчёркивает актуальность настоящего исследования.

Для определения направления сдвигов прогнозируемых оценок по сравнению с реальной оценкой, полученной на экзамене, был использован G-критерий знаков. Результаты отражены в таблице 1.

В группе испытуемых с завышенной САД отрицательные сдвиги между реальной и прогнозируемыми оценками являются типичными. G-критерий знаков показал, что сдвиг в типичную сторону достоверен ( $<<0.01)$, что статистически свидетельствует о завышении компонентов самооценки академических достижений.

Занижение компонентов САД также подтверждается с помощью G-критерия знаков (таблица 1). Следует отметить, что в рамках данной выборки в этой группе наблюдается выше академическая успеваемость по сравнению с предыдущей группой и больше совпадений желаемой и реальной оценок. Это говорит о том, что для студентов, которые хорошо учатся, характерен высокий уровень притязаний, удовлетворенность собой, личностная самооценка имеет тенденцию к завышению, отличается устойчивостью [5]. При этом уровень прогнозируемых оценок не влияет на уровень эмоционального напряжения, «проявляющегося в показателях тревожности, самочувствия, активности, настроения» [18, с. 159]. Но в то же время наименьший прирост показателя ситуационной тревожности отмечается у студентов, получивших «неудовлетворительно» на экзамене, а наибольший - у студентов, получивших «отлично» [18]. Занижение прогнозируемых оценок в данной группе, возможно, объясняется влиянием повышенного уровня психической напряженности, что статистически нашло подтверждение в данной работе.

Так же G-критерий знаков показал достоверность сдвига в типичную (отрицательную) сторону между желаемой и реальной оценкой в группе исследуемых с одноимённым названием. Ожидаемая и оценка себе при этом адекватны.

В таблице 2 представлены средние значения шкал в зависимости от адекватности САД.

В таблице 2 видно, что уровень психической напряженности перед экзаменом, личностно-ситуативная, пространственная, временная, общая прогностическая компетентность (ПК) отличаются в зависимости от адекватности САД. Для математического подтверждения гипотезы нами применен критерий Манна-Уитни (таблица 3).

Как показывает критерий Манна-Уитни и описательная статистика (таблицы 2 - 3), уровень психической напряженности в группе с завышенной желаемой оценкой (остальные прогнозируемые оценки адекватны) выше, чем в группе с адекватной самооценкой академических достижений на уровне значимых отличий $(p<0,05)$. Это объясняется высоким уровнем притязаний испытуемых и соответствующим повышением тревоги.

Личностно-ситуативная составляющая прогностической компетентности отражает коммуникативный уровень антиципации, то есть способность прогнозировать жизненные события и ситуации [9]. В настоящем исследовании не достигает статистически достоверных значений различия в уровне развития личностно-ситуативной прогностической компетентности в зависимости от САД.

«Пространственная составляющая прогностической компетентности демонстрирует способность предвосхищать перемещение предметов в пространстве, упреждать его, координировать собственные движения, проявляя моторную ловкость. Двигательная ловкость - это своего рода двигательная находчивость, но достаточно часто эта простейшая форма находчивости постепенно перерастает в умственную находчивость и изобре- 
Таблица 1.

Значения G-критерия знаков для групп с неадекватной самооценкой академических достижений

\begin{tabular}{|l|c|c|c|}
\multicolumn{1}{|c|}{ Показатели } & Завышенная САД & Заниженная САД & $\begin{array}{c}\text { Желаемая оценка завышена, } \\
\text { остальные адекватны }\end{array}$ \\
\hline Оценка желаемая — оценка реальная & $Z=0(p<0.01)$ & - & $Z=0$ ( $<<0.01)$ \\
\hline Оценка ожидаемая — оценка реальная & $Z=0(p<0.01)$ & $Z=0(p<0.01)$ & - \\
\hline Оценка себе — оценка реальная & $Z=0(p<0.01)$ & $Z=0(p<0.01)$ & - \\
\hline
\end{tabular}

Таблица 2.

Средние значения шкал в зависимости от адекватности самооценки академических достижений

\begin{tabular}{|l|c|c|c|c|c|}
\multicolumn{1}{|c|}{ Адекватность САД } & $\begin{array}{c}\text { Уровень психической } \\
\text { напряженности }\end{array}$ & $\begin{array}{c}\text { Личностно-ситуатив- } \\
\text { ная ПК }\end{array}$ & $\begin{array}{c}\text { Простран-ственная } \\
\text { ПК }\end{array}$ & Времен-ная ПК & Общая ПК \\
\hline Адекватная САД & 6,70 & 170,21 & 47,82 & 42,09 & 260,12 \\
\hline $\begin{array}{l}\text { Оценка желаемая завышена, } \\
\text { остальные адекватны }\end{array}$ & 8,30 & 167,59 & 44,67 & 36,70 & 248,96 \\
\hline Завышенная САД & 6,47 & 167,65 & 46,62 & 36,65 & 250,91 \\
\hline Заниженная САД & 7,11 & 166,67 & 43,03 & 38,63 & 248,32 \\
\hline
\end{tabular}

Разница значений шкал по критерию Манна-Уитни в группах в зависимости от САД

\begin{tabular}{|c|c|c|c|c|}
\hline Шкалы & $\begin{array}{c}\text { Адекватная САД - оценка } \\
\text { желаемая завышена }\end{array}$ & $\begin{array}{c}\text { Адекватная САД - } \\
\text { завышенная САД }\end{array}$ & $\begin{array}{c}\text { Адекватная САД - } \\
\text { заниженная САД }\end{array}$ & $\begin{array}{c}\text { Завышенная САД - } \\
\text { заниженная САД }\end{array}$ \\
\hline Уровень психической напряжённости & $U_{э м п}=541,5(p<0,05)$ & - & - & - \\
\hline Пространственная ПК & - & - & Uэмп $=966,5(p<0,05)$ & Uэмп $=921(p<0,05)$ \\
\hline Временная ПК & Uэмп $=492,5(p<0,01)$ & Иэмп $=333(p<0,01)$ & - & - \\
\hline Общая ПК & Uэмп $=532,5(p<0,05)$ & UэмП $=421(p<0,05)$ & Uэмп $=916,5(p<0,05)$ & - \\
\hline
\end{tabular}

тательность» [9, с. 92 - 93]. Нами выявлены различия в уровне данного параметра между группами с разной САД. Причем выше всех пространственная прогностическая компетентность у студентов с адекватной САД, а ниже всех - у субъектов, занижающих прогнозируемые оценки (таблицы $1-2$ ).

Временной аспект презентует хроноритмологические особенности личности: способность прогнозировать течение и точно распределять время, - что оказывает непосредственное влияние на осознание будущего, выработку плана дальнейших действий и умение принимать решения [9]. «Установки человека в отношении своего жизненного времени оказывают воздействие на его мотивационную сферу и регулируют поведение, хотя человек практически не осознает это влияние» [4, c. 82]. Значение временной прогностической компетентности выше у студентов с адекватной САД и ниже - с завышенной САД (уровень значимости 0.05). Другими словами, пунктуальные люди, умеющие распределять своё время, точнее прогнозируют свои возможности в экзаменационной ситуации.

Уровень общей прогностической компетентности значимо отличается в группах в зависимости от адекватности компонентов САД, что подтверждает одну из частей нашей гипотезы.

Коэффициент ранговой корреляции Спирмена помог определить обратную корреляцию на статистически значимом уровне между показателями психической напряжённости в экзаменационной ситуации и личностноситуативной прогностической компетентностью в группах с завышенной и заниженной САД ( $r s=-0.371(p<0.01)$ и rs $=-0.242(p<0.01)$ соответственно). Иначе говоря, чем выше уровень стресса, тем хуже субъект антиципирует значимые события и ситуации, включая уровень академических достижений, так как в состоянии повышенной психической напряженности поведение в значительной мере характеризуется преобладанием стереотипных ответов, неадекватных реакций [2].

Таким образом, можно сделать вывод, что наша гипотеза частично подтвердилась. Выявлены отличия степени психической напряженности, общего уровня прогностической компетентности студентов в зависимости от адекватности самооценки академических достижений. Субъектам, адекватно прогнозирующим свои академи- 
ческие достижения, свойственны моторная ловкость и умение точно распределять время. Настоящая работа, являясь пилотажным исследованием, определила обратную корреляцию уровня психической напряжённости и личностно-ситуативной прогностической компетентности в группах студентов с неадекватной самооценкой академических достижений.
Выявленные закономерности могут быть применены для разработки развития программы адекватности самооценки академических достижений, позволяющей снизить уровень стресса будущих профессионалов и повысить их возможности презентации своих компетенций в экзаменационной ситуации, что составляет перспективу исследования.

\section{ЛИТЕРАТУРА}

1. Абитов И.Р., Менделевич В.Д. Особенности совладающего поведения при психосоматических и невротических расстройствах // Вестник психиатрии и психологии Чувашии, 2008. - № 4. - URL: https://cyberleninka.ru/article/n/osobennosti-sovladayuschego-povedeniya-pri-psihosomaticheskih-i-nevroticheskihrasstroystvah (дата обращения: 30.04 .2020 ).

2. Бодров В.А. Психологический стресс: развитие и преодоление. - М.: Когито-Центр, 2015. - 562 с.

3. В мире рухнуло сразу все. Татьяна Черниговская о недоверии к информации и растерянном человеке. - URL: http://izbrannoe.com/news/mysli/v-mirerukhnulo-srazu-vsye-tatyana-chernigovskaya-0-nedoverii-k-informatsii-i-rasteryannom-cheloveke/ (дата обращения: 07.01.2020).

4. Волоткевич 0.В. Время как артефакт антиципации. // Новая наука и формирование культуры знаний современного человека. Сборник научных трудов / под ред. С.В. Кузьмина. - Казань: Издательство: Индивидуальный предприниматель Кузьмин Сергей Владимирович, 2018. - С. 79 — 83.

5. Дроздова Н.В. Особенности самооценки студентов с разной академической успеваемостью // Наука и современность, 2016. - № 46. - С. 54 — 59.

6. Жученко 0.А. Адекватность прогноза исхода экзаменационной ситуации как ресурс стрессоустойчивости личности: теоретический аспект. // Alma mater. Вестник высшей школы, 2013. - № 7. - С. 117 - 119.

7. Ломов Б.Ф., Сурков Е.Н. Антиципация в структуре деятельности. - М.: Наука, 1980. - 280 с.

8. Макарова Е.В. Модель формирования прогностической компетенции студентов аграрных вузов. // Казанский педагогический журнал, 2012. - URL: https://cyberleninka.ru/article/n/model-formirovaniya-prognosticheskoy-kompetentsii-studentov-agrarnyh-vuzov (дата обращения: 28.04.2020).

9. Менделевич В.Д. Антиципационные механизмы неврозогенеза. - М.: Издательский дом «Городец», 2018. - 448 с.

10. Ничипоренко Н.П. Прогностическая компетентность в системе личностных свойств. // Вопросы психологии, 2007. - № 2. - С. 123 - 130.

11. Ничипоренко Н.П., Менделевич В.Д. Феномен антиципационных способностей как предмет психологического исследования // Социальная и клиническая психиатрия, 1997. - № 2. - С. $31-36$.

12. Портал Федеральных государственных образовательных стандартов высшего образования. - URL http://fgosvo.ru/fgosvo/151/150/24/85 (дата 06ращения: 07.01.2020).

13. Словарь практического психолога / сост. С.Ю. Головин. - Мн.: Харвест, 1998. - 800 с.

14. Солобутина М.М. Антиципационная состоятельность в структуре профессиональной компетентности // Вестник ТГГУ, 2009. - №2 - 3 (17 - 18). - С. 133-137.

15. Сумина Н.Е., Ничипоренко Н.П. Взаимосвязь антиципационной состоятельности с личностными свойствами // Российский психологический журнал, 2007. - № 4. - URL: https://cyberleninka.ru/article/n/vzaimosvyaz-antitsipatsionnoy-sostoyatelnosti-s-lichnostnymi-svoystvami (дата 0бращения: 27.04.2020).

16. Фейгенберг И.М. Видеть - предвидеть - действовать. - М.: Знание, 1986. - 160 с.

17. Щербатых Ю.В. Психология стресса и методы коррекции. - СПб.: Питер, 2012. - 256 с.

18. Юматов Е.А. и др. Психофизиология эмоций и эмоционального напряжения студентов. - М.: Издательство ИТРК, 2017. - 200 c.

19. Jun S., Choi E. Academic stress and Internet addiction from general strain theory framework // Computers in Human Behavior. Vol. 49. August 2015. - P. 282-287. URL: https://dl.acm.org/doi/10.1016/j.chb.2015.03.001 (дата обращения 01.05.2020).

20. Rajoo K.S., Karam D.S., Aziz N.A.A. Developing an effective forest therapy program to manage academic stress in conservative societies: A multi-disciplinary approach // Urban Forestry \& Urban Greening. Vol. 4., July 2019. - URL: https://www.sciencedirect.com/science/article/pii/S1618866719300123. 